Lipid droplet remodelling during adipocyte transdifferentiation:

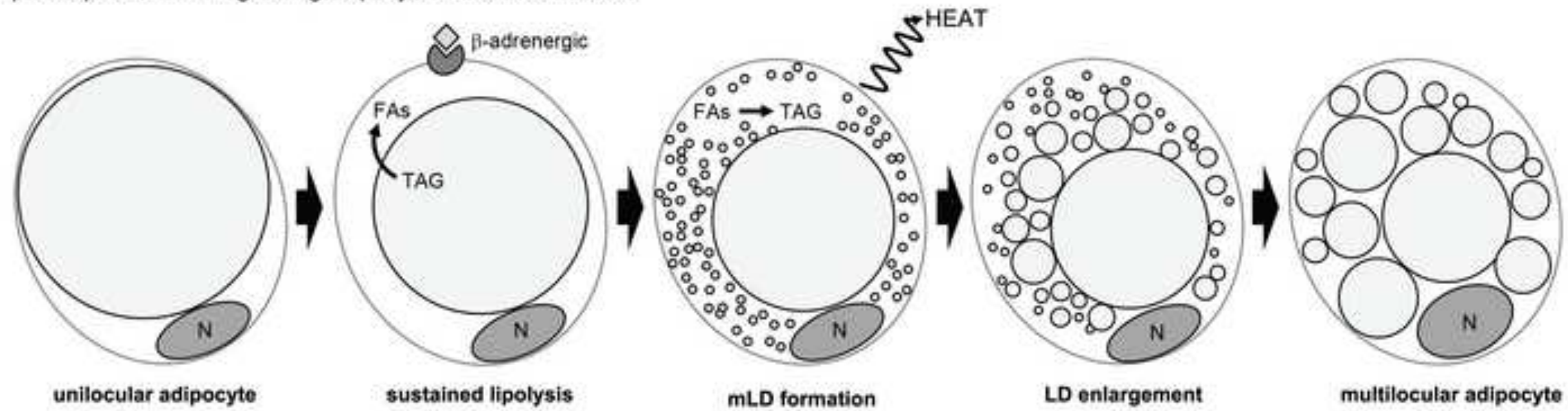


Highlights

Lipid droplet proteins are more highly expressed in BAT than WAT

Cold acclimatization induces Cidea, Gyk and pro-lipolytic proteins in WAT

$\beta$-adrenergic induction of lipid droplet formation and growth by lipid transfer

Thermogenic potential of the futile cycle of TAG hydrolysis and re-synthesis

Role of lipid droplet remodelling in unilocular to multilocular adipocyte transition 


\title{
Dynamic Changes in Lipid Droplet-Associated Proteins in the "Browning" of White Adipose Tissues
}

\section{David Barneda ${ }^{1}$, Andrea Frontini ${ }^{2}$, Saverio Cinti ${ }^{2,3}$, Mark Christian' ${ }^{1}$}

${ }^{1}$ Institute of Reproductive and Developmental Biology, Department of Surgery and Cancer, Imperial College London, Du Cane Road, London W12 ONN, UK

2 Department of Experimental and Clinical Medicine, University of Ancona, (Politecnica delle Marche), Via Tronto 10/A, 60126 Ancona, Italy.

3 The Adipose Organ Lab IRCCS San Raffaele Pisana, Via della Pisana, 23500163 Roma, Italy

\begin{abstract}
The morphological and functional differences between lipid droplets (LDs) in brown (BAT) and white (WAT) adipose tissue will largely be determined by their associated proteins. Analysing mRNA expression in mice fat depots we have found that most LD protein genes are expressed at higher levels in BAT, with the greatest differences observed for Cidea and Plin5. Prolonged cold exposure, which induces the appearance of brown-like adipocytes in mice WAT depots, was accompanied with the potentiation of the lipolytic machinery, with changes in ATGL, CGI-58 and G0S2 gene expression. However the major change detected in WAT was the enhancement of Cidea mRNA. Together with the increase in Cidec, it indicates that LD enlargement through LD-LD transference of fat is an important process during WAT browning. To study the dynamics of this phenotypic change, we have applied 4D confocal microscopy in differentiated 3T3-L1 cells under sustained $\beta$-adrenergic stimulation. Under these conditions the cells experienced a LD remodelling cycle, with progressive reduction on the LD size by lipolysis, followed by the formation of new LDs, which were subjected to an enlargement process, likely to be CIDE-triggered, until the cell returned to the basal state. This transformation would be triggered by the activation of a thermogenic futile cycle of lipolysis/lipogenesis and could facilitate the molecular mechanism for the unilocular to multilocular transformation during WAT browning.
\end{abstract}




\section{Abbreviations}

- LD, lipid droplet;

- BAT, brown adipose tissue;

- scWAT, subcutaneous white adipose tissue;

- gonWAT, periovarian white adipose tissue;

- mesWAT, mesenteric white adipose tissue;

- FAs, fatty acids;

- TAG, triacylglycerol;

- IBMX, isobutylmethylxanthine;

- $\quad$ PKA, protein kinase A;

- NLSD-I, neutral lipid storage disease with ichthyosis;

- ER, endoplasmic reticulum;

- ROS, reactive oxygen species;

\section{Key words}

Lipid droplets - adipose tissue - thermogenesis - transdifferentiation - lipolysis CIDEA

\section{Introduction}

Intracellular lipid droplets (LDs) are ubiquitous organelles present in all types of eukaryotic cells such as plants, mammals, algae and yeast [1-3]. Although they have a simple structure composed of a neutral lipid core surrounded by a phospholipid monolayer, the presence of LD-associated proteins provides a level of complexity and the ability to modulate key parameters such as their size, stability, inter-droplet interactions as well as regulatable lipid storage. Once considered passive accumulators of fat, the growing knowledge of the complexity of LD-based processes means that LDs are now emerging as dynamic organelles playing a central role in the regulation of lipid metabolism [4].

Adipocytes are specialized in the accumulation, storage and mobilization of neutral lipids in mammals and their LDs have specific properties not found in other cell 
types. While non-adipocyte cells usually contain tiny LDs (typically $<1 \mu \mathrm{m}$ ), adipocytes accumulate massive amounts of TAG in supersized LDs, which can be in the $100 \mu \mathrm{m}$ range [5]. White adipose tissue (WAT) acts as an energy depot, which stores lipids that are released into circulation when they are required. In contrast, brown adipose tissue (BAT) uses its stored fat to generate heat by oxidation of fatty acids to maintain the body temperature [6]. Their different functions are reflected in their morphology, as white adipocytes usually contain a single giant LD occupying most of the cytoplasm (unilocular), while brown adipocytes, rich in mitochondria, are filled with a number of smaller LDs (multilocular). Large LDs offer the more efficient form of fat storage, whereas smaller LDs, with higher surface/volume ratio, will facilitate the release of their stored lipids given the extensive surface accessible to lipases.

The recent identification of BAT in adult humans has stimulated the exploration of its potential role in obesity or type 2 diabetes therapies [7, 8]. An especially promising strategy is based on the promotion of brown fat properties in WAT, in other words, the browning of white adipocytes. Following prolonged cold exposure, multilocular UCP1positive adipocytes appear in WAT depots [9, 10]. It has been suggested that they represent a third kind of adipocyte, named beige or BRITE (brown in white) cells, which resemble white cells in basal conditions but acquire a brown phenotype during cold acclimatization [11, 12]. An alternative to the presence of a specific subset of switchable BRITE cells within white depots is that brown-like cells could originate by the transdifferentiation of classic white adipocytes, which would have the inherent ability to acquire brown features [13-15]. In any case, the phenotypic transformation experienced by WAT cells at cold temperatures will imply profound changes in the proteins controlling the LDs.

In this article we discuss the role of the main LD proteins in adipocytes and show their adipose tissue depot-specific expression pattern and regulation after the acclimatization of mice to cold temperatures. In addition, using $4 \mathrm{D}$ confocal microscopy, we have monitored the adipocyte LD dynamics during sustained $\beta$ adrenergic stimulation, modelling the phenotypic transformation involved in white to brown adipocyte transdifferentiation.

\section{Material and Methods}




\subsection{Mice treatment and gene expression analysis}

Sv129 female mice (10 week old) were maintained at $28^{\circ} \mathrm{C}, 22^{\circ} \mathrm{C}$, or $6^{\circ} \mathrm{C}$ for 10 days. Adipose tissues were dissected and either snap frozen or fixed in neutral buffered formalin. RNA was prepared from the snap frozen tissue using Tri Reagent (Invitrogen) and reverse transcribed to cDNA using M-MLV reverse transcriptase (Invitrogen). Quantitative real-time PCR was performed on an ABI 7900HT system (Applied Biosystems) using the JumpStart Taq polymerase kit (Sigma-Aldrich). Gene expression levels were normalized relative to $\beta$-tubulin mRNA. The primers used for each gene are listed in Supplemental Table 1.

\subsection{Light microscopy and immunohistochemistry}

Immediately after removal, adipose tissues were fixed overnight by immersion at $4^{\circ} \mathrm{C}$ in $4 \%$ paraformaldehyde in $0.1 \mathrm{M}$ phosphate buffer ( $\mathrm{pH} 7.4$ ). They were then dehydrated, cleared, and paraffin-embedded. Sections from 3 different levels $(100 \mu \mathrm{m}$ apart) were hematoxylin and eosin stained to assess morphology and for immunohistochemistry. UCP1 or CIDEA immunoreactivity was examined as follows. For each section level, $3 \mu \mathrm{m}$ thick, dewaxed sections were incubated with rabbit antiUCP1 (1:500 v/v, Abcam, cat \# 10983) or rabbit anti-CIDEA (1:200 v/v; SigmaAldrich, cat \# C7977), according to the avidin-biotin complex (ABC) method. Briefly, endogenous peroxidase was blocked with 3\% hydrogen peroxide in methanol; sections incubated in normal goat serum (1:75) for $20 \mathrm{~min}$ to reduce nonspecific background; incubated with primary antibodies against UCP1 or CIDEA overnight at $4{ }^{\circ} \mathrm{C}$; incubated with goat anti-rabbit IgG biotin conjugated (1:200; Vector Labs); detection with ABC kit (Vector Labs) and enzymatic reaction to reveal peroxidase with Sigma Fast 3,3'diaminobenzidine (Sigma-Aldrich) as substrate. Finally, sections were counterstained with hematoxylin and mounted in Eukitt (Fluka). All observations were performed with a Nikon Eclipse 80i light microscope. The images were stored as TIFF files. Brightness and contrast of the final images were adjusted using Adobe Photoshop.

\subsection{Cell culture}

3T3-L1 cells were cultured in glass bottom dishes (MatTek Corp.) previously coated with gelatin. The undifferentiated cells were grown in Dulbecco's modified Eagle's medium (DMEM) containing $4.5 \mathrm{~g} / \mathrm{l}$ glucose and L-glutamine (Invitrogen) supplemented with $10 \%$ newborn calf serum (Invitrogen) and antibiotics at $37^{\circ} \mathrm{C}$ and 
$5 \% \mathrm{CO}_{2}$. Two days after confluence, cell differentiation was initiated with DMEM with $10 \%$ fetal bovine serum (FBS, Invitrogen), $500 \mu \mathrm{M}$ isobutylmethylxanthine (IBMX) (Sigma-Aldrich), $0.25 \mu \mathrm{M}$ dexamethasone (Sigma-Aldrich) and $170 \mathrm{nM}$ insulin (SigmaAldrich). After 48 hours medium was changed to DMEM with 10\% FBS and $170 \mathrm{nM}$ insulin, and replenished every two days for 8-10 days.

\subsection{D confocal imaging}

The differentiated 3T3-L1 cells were washed with DMEM and incubated in DMEM with HEPES (Invitrogen) containing 0.1 $\mu \mathrm{g} / \mathrm{ml}$ BODIPY 493/503 (Invitrogen). After 10 minutes at $37^{\circ} \mathrm{C}$, FBS was added to a final concentration of $10 \%$ and the dish was positioned in a Leica SP5 confocal microscope with a 63× Plan-APO, 1.4 NA oil immersion objective and equilibrated at $37^{\circ} \mathrm{C}$ for 30 minutes. The imaging was initiated after the addition of IBMX $(500 \mu \mathrm{M})$ and isoproterenol $(10 \mu \mathrm{M})$. The cells were recorded during 15 hours on a xyzt configuration, using 5\% of the argon laser power on the $488 \mathrm{~nm}$ excitation channel. Z-stack confocal images were acquired every 1 or 2 minutes, and the time-lapse series were represented as their maximum projection and managed with ImageJ (National Institutes of Health) and Adobe Photoshop. 


\section{Results and Discussion}

\subsection{LD protein gene expression in mouse white and brown adipose tissue depots}

To investigate the importance of the main LD proteins (Table 1) in white and brown adipose tissue, we analysed their gene expression in interscapular BAT and three WAT depots: subcutaneous (scWAT), gonadal (gonWAT) and mesenteric (mesWAT) (Fig. 1). Our results clearly show that for most of the LD proteins, their mRNA levels are much higher in BAT than in WAT. This suggests a quantitatively greater involvement of LD-associated processes in the brown adipocytes, as well as a major complexity in LD dynamics of these cells. The adipose tissues are composed of lipidfilled mature adipocytes and other non-adipocyte cells, which form the stromal vascular fraction that consists of various types of cells, including immune cells, fibroblasts, pericytes, endothelial cells, adipocyte progenitors, and stromal cells, as well as undefined pool of stem cells. Although all these cells will contain LDs and associated proteins, adipocytes will be the predominant site of LD-associated protein gene expression in the adipose tissue. Considering that these proteins are coating the LDs, and that the total LD surface is higher in multilocular adipocytes, it is not surprising that brown fat cells will require higher levels of LD proteins. Among the studied genes, only Plin4, Cidec and Cav1 exhibit similar expression levels in BAT, scWAT and gonWAT depots, indicating that they are particularly important for WAT function. Mettl7b results should be interpreted with caution, as it is poorly expressed in adipose tissue (Expression profiling of mouse tissues using Affymetrix Mouse MOE430 2.0 chips, data available at http://biogps.org [61, 62]). In contrast, mesWAT expressed the lowest levels of all LD protein genes, indicating a more passive role of LDs in the physiology of mesenteric adipocytes.

Despite most of the analysed genes showing higher mRNA levels in BAT than WAT, two factors stand out as expressed at much greater levels in BAT compared to WAT: Cidea and Plin5. This BAT-specific expression highlights them as markers for brown adipocytes. CIDEA is a multifunctional protein that is involved in apoptosis and transcriptional regulation but its most clearly defined role in adipocytes is the promotion of LD enlargement [33, 35]. Its molecular mechanism is the same as for CIDEC, 
inducing LD growth through a slow transference of fat between LDs [37], and both proteins seem to be responsible for the formation of the large LDs found in brown and white adipocytes. Despite the similarity in the sequence and function of CIDEA and CIDEC, the specific expression of Cidea in BAT indicates a differential role of these proteins. During adipocyte differentiation, LD enlargement is likely to be produced by the CIDE-triggered transference of fat [63]. However, while this slow LD fusion will continue indefinitely in white adipocytes until only one single giant LD remains in the cell, in brown adipocytes the LDs must stop its fusion-like events once they have achieved a certain size, in order to maintain their multilocular morphology. It is reasonable to consider that, among other factors, this disparate behaviour of WAT and BAT in relation to LD growth may be regulated by the relative levels of CIDEA in relation to CIDEC. The elevated Cidec expression in mature WAT, where the unilocular LDs are already formed, may support LD-LD lipid transfer events in this tissue, either for LD growth in differentiating adipocytes or for the integration of newly formed LDs to the unilocular LD in mature adipocytes.

\subsection{Effect of cold exposure on LD protein gene expression}

WAT depots can respond to a long term cold stimulus by specific genetic and morphological changes that result in a more BAT-like appearance [9, 64]. The regulation of acute changes in LD dynamics and metabolism in adipocytes, is largely achieved by postranslational modifications of LD-proteins such as the phosphorylation of PLIN1 or changes in protein stability. However, the adaptation to long-term environmental variations may also involve the regulation of the adipocyte LD proteins at the transcriptional level. To study the alterations in LD-proteins induced by prolonged cold exposure, we compared their mRNA levels in selected fat depots of Sv129 mice maintained at thermoneutrality $\left(28^{\circ} \mathrm{C}\right)$ or $6^{\circ} \mathrm{C}$ for 10 days.

Comparing the different WAT depots, we observed that both gonWAT and scWAT react to cold temperature by increasing the expression of several LD-protein genes, indicating a potentiation of LD-based processes (Fig. 2A). In contrast mesWAT shows a weaker response, demonstrating that it is less sensitive to temperature than other fat depots. While fat depots are heterogeneous and may simultaneously contain white and brown cells [65], the mesenteric depot seems to be especially rich in white unilocular adipocytes and less prone to acquire brown features [66], which may explain both its low expression levels of LD proteins and resistance to cold-induced changes (Fig. 1 and 
2A). The gene expression alterations experienced in subcutaneous and gonadal WAT show that the mice react to cold temperature by enhancing the lipolytic capacity in these WAT depots. This is reflected by increases in the mRNA levels of the lipase ATGL and its activator CGI-58, as well as the reduction of its inhibitor G0S2 in the case of scWAT (Fig. 2A). These prolipolytic modifications fit with the expected increase in the mobilization of FAs in a situation of higher energy demand. In contrast, these genes are not greatly affected in BAT, where they are maintained at high expression levels independently of the environmental temperature. In addition to these genes, Rab18 and the different Cides are also enhanced in WAT at $6{ }^{\circ} \mathrm{C}$, indicating that their cellular roles may be required in this prolipolytic state.

The processes taking place in each LD will be determined by both the absolute levels of each LD protein and the relative protein combinations found in their surface. The ratios of the PLINs will be especially affected in BAT, where Plin1 and Plin3 expression was enhanced while Plin2 was highly reduced (Fig. 2A). In contrast, Plin2 was enhanced in subcutaneous and gonadal WAT depots, showing that the LD remodelling processes taking place during cold exposure differs between BAT and WAT. The expression pattern of Plin5 resembles the lipolytic machinery, being increased in WAT and not affected in BAT. As Plin5 in adipose tissue is largely confined to brown cells, its increased expression in WAT is another indicator of the acquisition of brown features. In this situation, with enhanced lipolysis in WAT, PLIN5 could be involved in lipolysis regulation or in protecting the cell against excessive ROS produced by FA oxidation $[31,32]$.

The major change observed among all the genes analysed is the increase in Cidea mRNA in gonWAT (Fig. 2A). The histological analysis of gonWAT also showed an increase on CIDEA immunostaining after cold exposure (Fig. 2B). As Cidea is predominantly expressed in BAT, its cold-induced increase in WAT suggests that it could be an important effector during the browning process. The gonWAT depot of mice kept at $28{ }^{\circ} \mathrm{C}$ is predominantly composed by unilocular UCP1-negative adipocytes, but it also contains areas rich in brown-like multilocular cells, which can express moderate levels of UCP1. As previously described [66], after cold acclimatization, both UCP1 expression and the percentage of multilocular cells are highly increased in WAT, indicating the browning of the tissue (Fig. 2B). Despite the induction of UCP1, the presence of multilocular UCP1-negative cells is clearly 
observed in these conditions, and it has been suggested that they may represent intermediates of the transdifferentiation process [15, 66-68]. In contrast, CIDEA appears broadly expressed in most of the multilocular cells (Fig. 2B), indicating that its induction could be an earlier event in the browning process, probably involved in the acquisition of a multilocular morphology.

Overall, the changes in LD-protein gene expression suggest that LDs experience a different adaptation to cold exposure in WAT and BAT cells. It is likely that the transcriptional regulators that change upon cold exposure determine the dynamic expression of LD-associated proteins. Factors central to the adaptation to cold include PGC-1 $\alpha$, which functions as a co-activator for NRs including PPARs and ERRs, which are themselves induced by low temperatures [69, 70]. PLIN5, which is regulated by PPAR $\alpha$ and PPAR $\gamma$ [27], may be elevated in BAT and induced following cold exposure due to the increased levels of PPAR $\alpha$ and its co-regulator PGC- $1 \alpha$. Similarly, CIDEA is regulated, at least in the liver, by PPAR $\alpha$ [71], although in adipose tissue ERR $\alpha$ and the balance between the coregulators PGC-1 $\alpha$ and RIP140 is more likely to be important for determination of its expression level [34]. PPAR $\gamma$ seems to be most important for the expression of CIDEC [72] and ATGL [73, 74]. Furthermore, a positive feedback loop may be facilitated by the products of lipolysis, due to ATGL, acting as ligands for PPARs [75]. Further studies are required to determine the full repertoire of transcriptional regulators that control expression of LD-associated proteins.

\subsection{LD dynamics during sustained $\beta$-adrenergic stimulation}

Adipose tissue is innervated by the sympathetic nervous system, which during cold exposure will trigger thermogenesis through the stimulation of $\beta$-adrenergic receptors in adipocytes [6]. This acute stimulus will activate lipolysis in adipocytes, liberating FAs for $\beta$-oxidation and heat generation in BAT, or for exportation in the case of WAT. Over time, the prolonged exposure to cold temperatures will promote an adaptive change in WAT, leading to the acquisition of a BAT-like phenotype, with the appearance of multilocular UCP1-positive adipocytes $[9,10]$. The origin of these cells is still being debated, although increasing data supports that rather than derived from preadipocytes present in WAT, they originate from mature adipocytes, which would undergo a phenotypic transformation to acquire brown-like features [15]. This transdifferentiation process could be restricted to a subset of adipocytes, the so-called 
BRITE cells [11], or be an inherent feature of any kind of white adipocyte [14]. Independent of their cellular lineage, it requires a morphological transformation in which, alongside changes in Ucp1 expression and mitochondria number, a unilocular adipocyte is ultimately transformed into a multilocular cell.

This transformation is triggered by prolonged cold exposure or chronic $\beta$-adrenergic stimulation, but the mechanism leading from unilocular to multilocular is still unknown and must require profound changes in the LD cell biology. To monitor in vitro the changes experienced by adipocytes during prolonged $\beta$-adrenergic stimulation we applied 4D confocal microscopy to differentiated 3T3-L1 adipocytes stimulated with isoproterenol and IBMX, which promote a sustained elevation of cAMP levels and thus a continuous activation of lipolysis [76]. The LDs were stained with a low dose of BODIPY 493/503 $(0.1 \mu \mathrm{g} / \mathrm{ml})$ and a low laser power was used for their confocal analysis, so that toxicity was reduced, allowing the recording of LD dynamics at small time-lapse intervals (1-2 min) during a relatively long period of time (up to 15 hours).

A progressive reduction in the size of LDs was observed after the addition of IBMX and isoproterenol due to the sustained activation of lipolysis (Fig. 3A and supplemental movie S1). Shortly after the start of the $\beta$-adrenergic stimulation, a number of small LDs or microLDs (mLDs) appeared throughout the cytoplasm, increasing in number during the next hours. This postlipolytic appearance of mLDs has previously been attributed to the fission of the pre-existing large LDs [76]. However, current evidence indicates that they are de novo synthesized LDs, produced throughout the cell with close association with the ER $[63,77]$.

Simultaneously following the progression of different cells in each experiment, we observed that after the first stages of sustained lipolysis and mLD production, during which the cytoplasm was filled with tiny mLDs, the cells could proceed in 3 alternative ways (Fig. 3A). In some adipocytes the lipolysis progressed until only a few mLDs remained present, indicating that most of the fat initially contained in the LDs was efficiently exported or consumed (Fig. 3B). A small fraction of cells died a few hours after the beginning of lipolysis, probably because they were unable to process the toxic amounts of FAs produced. However, the most striking behaviour was observed 4-6 hours after the start of lipolysis (in over $40 \%$ of cells recorded) wherein the newly formed mLDs were subjected to a continuous enlargement process, returning the cell to its initial state (Fig. 3C and supplemental Movie S1). This cycle of LD remodelling has 
been recently observed by the Parton group using a similar approach, although in their experimental system the postlipolytic LD enlargement was only achieved after the removal of the lipolytic stimulus and the addition of insulin [77]. Here, we show that during sustained lipolytic stimulation, leading to massive mLD production, a fraction of the adipocytes are able to use these newly synthetized mLDs to form large LDs without changing the culture conditions. In these cells, the lipolysis-driven reduction in the size of the initial LDs continues even when the mLDs have started their enlargement process (Fig. 3D), revealing that both processes can take place simultaneously in a single cell. As the different LDs in a single cell can be coated with different LD-proteins, this opposing behaviour indicates a selective protein sorting among old and newly formed LDs.

The observed LD growth process take place through a transfer of fat between LDs, in which one LD grows by absorbing the lipid content of its neighbour LD until this slow and controlled fusion is completed (Fig. 3E). This unexpected mechanism has been recently described by two independent groups in postlipolytic and in differentiating adipocytes $[63,77]$, and it is analogous to the newly revealed mechanism of action for CIDEC and CIDEA in LD enlargement [37]. According to this, both CIDEC and CIDEA can promote the complete transference of lipids from a donor LD to an acceptor one. During this enlargement process we observed that the mLDs, which showed a random motion pattern, acquired a more organized behaviour, displaying a directed displacement from the periphery, where they were continuously formed, to the cell centre, where they were absorbed by the growing LDs (Supplemental movie S1). Interestingly, during the transition period between the mLD production and enlargement phases, a dramatic increase in cell motility was observed, involving continuous changes in cell shape and motility. This phenomenon, together with the requirement of microtubule integrity for postlipolytic LD enlargement [77], indicates that the LD growth process is facilitated by a reorganization of the adipocyte cytoskeleton and the molecular machinery responsible for LD motion.

Recording the LD enlargement at short time-lapse intervals (1-2 min), we observed that while the complete transference of fat among large LDs is a slow process, it can be completed in few minutes when it involves smaller LDs (Supplemental movie S1). Thus, the apparent LD fusion process observed using longer frame intervals (15 min) [77] may in reality be a lipid transfer event. The ectopic expression of CIDE 
proteins in virtually any cell line induces the appearance of large LDs, formed by the combination of the tiny mLDs found in these cells $[35,40]$. This reveals that CIDEdependent transfer of fat is not only effective on relatively large LDs but it is enough to induce the enlargement of mLDs. In our opinion, despite other growth mechanisms such as LD fusion, in situ TAG synthesis or TAG import from the ER, could contribute to the early stages of mLD enlargement, the main mechanism involved in the formation of the characteristic adipocyte macroLDs is the slow and regulated LD-LD transference of lipids controlled by CIDE proteins.

\subsection{Role of $L D$ remodelling in adipocyte transdifferentiation}

The cycle of lipolysis, mLD formation and their later enlargement observed in cultured adipocytes exposed to sustained $\beta$-adrenergic stimulation (Fig. 3C) may have a physiological role during cold acclimatization. The re-esterification of released FAs and accumulation in newly formed mLDs is cytoprotective against the toxic effects of excessive FAs produced during periods of enhanced lipolysis [78]. However, adipocytes may clear the lipolysis-derived FAs by other mechanisms, such as $\beta$-oxidation or FA exportation (Fig. 5A), so mLD formation could be related to other aspects of the adipocyte physiology.

The low LD surface/volume ratio in unilocular adipocytes hinders lipolysis, so an alternative function of post-lipolytic mLD formation could be to raise lipolysis efficiency by increasing the total surface area accessible to lipases. In fact, it has been suggested that in white adipocytes lipolysis is mainly performed in a subset of small LDs in the periphery of the large unilocular droplet [79]. This model implies that TAG has to be transferred from the main store to the lipolytically active smaller LDs to facilitate TAG breakdown. Interestingly, the existence of TAG traffic between LDs has been recently demonstrated in a paper showing how CIDE proteins accumulate at the LD-LD contact site and promote TAG transfer among them [37]. The presence of these TAG-permeable CIDE-enriched domains in the LD-LD contact sites could constitute an interconnected LD network, where the TAG hydrolyzed at the mLDs could be continuously replenished with TAG from larger LDs (Fig. 5B). This could explain why the expression of CIDE proteins is enhanced in WAT after cold exposure despite the primary function of these proteins is to promote LD enlargement (Fig. 2). In addition, if the cell could control the preferred direction of the CIDE-dependent TAG transference 
among LDs, it would determine the acquisition of a unilocular morphology (small LD to large LD transfer) or multilocular (large to small transfer).

Using a approach similar to our time-lapse experiments, Paar et al., demonstrated that postlipolytic mLD biogenesis can be prevented by the addition of BSA to sequester the FAs exported to the extracellular medium or by the inhibition of FA activation with triacsin $C$ [63]. This observation indicates that the mLDs originated after sustained $\beta$-adrenergic activation are formed by the recycling into TAG of the FA molecules simultaneously released by lipolysis. In adipocytes, this futile cycle of TAG hydrolysis and re-synthesis can be prevented by suppressing the expression of glycerol kinase (Gyk), the activity of which is required for the recycling of glycerol and FAs to form TAG (Fig. 5A). PPAR $\gamma$ ligands such as thiazolidinediones (TZDs) have been described to promote this cycle by inducing the expression and activity of GYK in adipocytes, which may contribute to their antidiabetic properties by reducing excessive circulating FAs [80]. To assess if the lipolysis/lipogenesis cycle observed in our in vitro studies is also favoured in WAT during cold acclimatization, we measured the expression levels of Gyk in the adipose depots of mice kept at $28{ }^{\circ} \mathrm{C}$ and $6{ }^{\circ} \mathrm{C}$ (Fig. 4A). The expression of Gyk, as well as the mRNA levels of the adipocyte glycerol transporter Aquaporin7 (Aqp7), were increased in WAT after cold exposure, indicating that the cells enhance both recycling and exporting mechanisms to process the metabolites released under sustained lipolysis. Comparing the expression of these genes in BAT and WAT of mice kept at $22{ }^{\circ} \mathrm{C}$, we observed that Gyk is most highly expressed in BAT (Fig. 4B). These results reveal that the futile metabolic cycle of TAG facilitated by GYK activity could be important for BAT physiology as well as for the browning of WAT. As the chemical energy expended in this lipolysis/lipogenesis cycle will be ultimately released as heat (Fig. 5A), it may constitute a thermogenic process like other ATP-consuming futile cycles [81]. The observed viability of Ucpl knockout mice when acclimatized to the cold reveals the presence UCP1-independent thermogenic mechanisms [82-84]. Interestingly, in the Ucpl knockout mice, Cidea was dramatically induced in WAT by cold exposure, indicating that it may participate in cold acclimatization mechanisms independent of UCP1 [82].

While in vitro adipocyte models like the 3T3-L1 cells used in this study present a multilocular morphology, it is reasonable that the observed cycle of $\mathrm{mLD}$ formation and enlargement can occur in vivo by unilocular WAT cells submitted to persistent 
lipolysis stimulation. This possibility has important implications for the understanding of the cellular mechanism responsible for the phenotypic transformation experienced by unilocular adipocytes during WAT browning. Thus, after sustained $\beta$-adrenergic stimulus induced by cold, the unilocular white or BRITE adipocytes may undergo a continuous lipolytic process leading to the formation of mLDs that would grow by the lipid transfer process triggered by CIDE proteins (Fig. 5C). In addition, this enlargement process may be accelerated by CIDE-dependent transference of TAG from the unilocular LD to the growing ones. Ultimately, this LD remodelling would produce a multilocular adipocyte that would acquire further brown features, including UCP1 expression and increased mitochondrial number. Among the changes involved in WAT browning, an early modification will be the increase in CIDEA and CIDEC expression (Fig. 2), which will be required for the enlargement of the newly formed mLDs. The presence of CIDEA-positive, UCP1-negative multilocular adipocytes in WAT depots of mice kept at $6{ }^{\circ} \mathrm{C}$ supports this model, indicating that the LD remodelling is an early stage on adipocyte transdifferentiation (Fig 2 B). Considering that the formation of a multilocular adipocyte from a unilocular one by this mechanism requires an almost complete hydrolysis of the unilocular LD and the re-synthesis of massive amounts of TAG, this process will represent a substantial release of energy which may significantly contribute to the thermogenic activity of the browning WAT.

\section{Conclusions}

Understanding the molecular cell biology of WAT browning during cold exposure is necessary for the development of its therapeutic potential in obesity and diabetes. Given our results in relation to LD dynamics and the expression of LD-associated proteins, we consider that the transdifferentiation of white unilocular adipocytes could involve among other changes, a thermogenic cycle of TAG hydrolysis and resynthesis to form mLDs, which will subsequently be enlarged until the cell achieves the multilocular morphology of brown adipocytes. This process will be promoted by the sustained activation of the lipolytic machinery, the recycling of FAs and glycerol into TAG favoured by Gyk expression, the packaging of this TAG in new mLDs and their successive enlargement by CIDE proteins.

\section{Acknowledgements}


This work was supported by the BBSRC grant BB/H020233/1, the EU FP7 project DIABAT (HEALTH-F2-2011-278373), and the Genesis Research Trust.

\section{References}

[1] T.C. Walther, R.V. Farese, Jr., Lipid droplets and cellular lipid metabolism, Annu Rev Biochem 81 (2012) 687-714.

[2] D.L. Brasaemle, N.E. Wolins, Packaging of fat: an evolving model of lipid droplet assembly and expansion, J Biol Chem 287 (2011) 2273-2279.

[3] T. Fujimoto, R.G. Parton, Not just fat: the structure and function of the lipid droplet, Cold Spring Harb Perspect Biol 3 (2011).

[4] R.V. Farese, Jr., T.C. Walther, Lipid droplets finally get a little R-E-S-P-E-C-T, Cell 139 (2009) 855-860.

[5] M. Suzuki, Y. Shinohara, Y. Ohsaki, T. Fujimoto, Lipid droplets: size matters, J Electron Microsc (Tokyo) 60 Suppl 1 (2011) S101-116.

[6] B. Cannon, J. Nedergaard, Brown adipose tissue: function and physiological significance, Physiol Rev 84 (2004) 277-359.

[7] K.A. Virtanen, M.E. Lidell, J. Orava, M. Heglind, R. Westergren, T. Niemi, M. Taittonen, J. Laine, N.J. Savisto, S. Enerback, P. Nuutila, Functional brown adipose tissue in healthy adults, N Engl J Med 360 (2009) 1518-1525.

[8] A.M. Cypess, C.R. Kahn, Brown fat as a therapy for obesity and diabetes, Curr Opin Endocrinol Diabetes Obes 17 (2010) 143-149.

[9] B. Cousin, S. Cinti, M. Morroni, S. Raimbault, D. Ricquier, L. Penicaud, L. Casteilla, Occurrence of brown adipocytes in rat white adipose tissue: molecular and morphological characterization, J Cell Sci 103 ( Pt 4) (1992) 931-942.

[10] P. Young, J.R. Arch, M. Ashwell, Brown adipose tissue in the parametrial fat pad of the mouse, FEBS Lett 167 (1984) 10-14.

[11] J. Wu, P. Bostrom, L.M. Sparks, L. Ye, J.H. Choi, A.H. Giang, M. Khandekar, K.A. Virtanen, P. Nuutila, G. Schaart, K. Huang, H. Tu, W.D. van Marken Lichtenbelt, J. Hoeks, S. Enerback, P. Schrauwen, B.M. Spiegelman, Beige adipocytes are a distinct type of thermogenic fat cell in mouse and human, Cell 150 (2012) 366-376.

[12] N. Petrovic, T.B. Walden, I.G. Shabalina, J.A. Timmons, B. Cannon, J. Nedergaard, Chronic peroxisome proliferator-activated receptor gamma (PPARgamma) activation of epididymally derived white adipocyte cultures reveals a population of thermogenically competent, UCP1-containing adipocytes molecularly distinct from classic brown adipocytes, J Biol Chem 285 (2009) 7153-7164.

[13] J. Himms-Hagen, A. Melnyk, M.C. Zingaretti, E. Ceresi, G. Barbatelli, S. Cinti, Multilocular fat cells in WAT of CL-316243-treated rats derive directly from white adipocytes, Am J Physiol Cell Physiol 279 (2000) 670-681.

[14] S. Cinti, Adipocyte differentiation and transdifferentiation: plasticity of the adipose organ, J Endocrinol Invest 25 (2002) 823-835.

[15] G. Barbatelli, I. Murano, L. Madsen, Q. Hao, M. Jimenez, K. Kristiansen, J.P. Giacobino, R. De Matteis, S. Cinti, The emergence of cold-induced brown adipocytes in mouse white fat depots is determined predominantly by white to brown adipocyte transdifferentiation, Am J Physiol Endocrinol Metab 298 (2010) 1244-1253.

[16] A.S. Greenberg, J.J. Egan, S.A. Wek, N.B. Garty, E.J. Blanchette-Mackie, C. Londos, Perilipin, a major hormonally regulated adipocyte-specific phosphoprotein associated with the periphery of lipid storage droplets, J Biol Chem 266 (1991) 11341-11346.

[17] H. Wang, L. Hu, K. Dalen, H. Dorward, A. Marcinkiewicz, D. Russell, D. Gong, C. Londos, T. Yamaguchi, C. Holm, M.A. Rizzo, D. Brasaemle, C. Sztalryd, Activation of hormone- 
sensitive lipase requires two steps, protein phosphorylation and binding to the PAT-1 domain of lipid droplet coat proteins, J Biol Chem 284 (2009) 32116-32125.

[18] H. Miyoshi, J.W. Perfield, 2nd, S.C. Souza, W.J. Shen, H.H. Zhang, Z.S. Stancheva, F.B. Kraemer, M.S. Obin, A.S. Greenberg, Control of adipose triglyceride lipase action by serine 517 of perilipin A globally regulates protein kinase A-stimulated lipolysis in adipocytes, J Biol Chem 282 (2007) 996-1002.

[19] J.T. Tansey, C. Sztalryd, J. Gruia-Gray, D.L. Roush, J.V. Zee, O. Gavrilova, M.L. Reitman, C.X. Deng, C. Li, A.R. Kimmel, C. Londos, Perilipin ablation results in a lean mouse with aberrant adipocyte lipolysis, enhanced leptin production, and resistance to dietinduced obesity, Proc Natl Acad Sci U S A 98 (2001) 6494-6499.

[20] H.P. Jiang, G. Serrero, Isolation and characterization of a full-length cDNA coding for an adipose differentiation-related protein, Proc Natl Acad Sci U S A 89 (1992) 7856-7860.

[21] D.L. Brasaemle, T. Barber, N.E. Wolins, G. Serrero, E.J. Blanchette-Mackie, C. Londos, Adipose differentiation-related protein is an ubiquitously expressed lipid storage droplet-associated protein, J Lipid Res 38 (1997) 2249-2263.

[22] C. Sztalryd, M. Bell, X. Lu, P. Mertz, S. Hickenbottom, B.H. Chang, L. Chan, A.R. Kimmel, C. Londos, Functional compensation for adipose differentiation-related protein (ADFP) by Tip47 in an ADFP null embryonic cell line, J Biol Chem 281 (2006) 34341-34348.

[23] M. Bell, H. Wang, H. Chen, J.C. McLenithan, D.W. Gong, R.Z. Yang, D. Yu, S.K. Fried, M.J. Quon, C. Londos, C. Sztalryd, Consequences of lipid droplet coat protein downregulation in liver cells: abnormal lipid droplet metabolism and induction of insulin resistance, Diabetes 57 (2008) 2037-2045.

[24] N.E. Wolins, B. Rubin, D.L. Brasaemle, TIP47 associates with lipid droplets, J Biol Chem 276 (2001) 5101-5108.

[25] N.E. Wolins, B.K. Quaynor, J.R. Skinner, M.J. Schoenfish, A. Tzekov, P.E. Bickel, S3-12, Adipophilin, and TIP47 package lipid in adipocytes, J Biol Chem 280 (2005) 1914619155.

[26] N.E. Wolins, J.R. Skinner, M.J. Schoenfish, A. Tzekov, K.G. Bensch, P.E. Bickel, Adipocyte protein S3-12 coats nascent lipid droplets, J Biol Chem 278 (2003) 37713-37721.

[27] N.E. Wolins, B.K. Quaynor, J.R. Skinner, A. Tzekov, M.A. Croce, M.C. Gropler, V. Varma, A. Yao-Borengasser, N. Rasouli, P.A. Kern, B.N. Finck, P.E. Bickel, OXPAT/PAT-1 is a PPAR-induced lipid droplet protein that promotes fatty acid utilization, Diabetes 55 (2006) 3418-3428.

[28] K.T. Dalen, T. Dahl, E. Holter, B. Arntsen, C. Londos, C. Sztalryd, H.I. Nebb, LSDP5 is a PAT protein specifically expressed in fatty acid oxidizing tissues, Biochim Biophys Acta 1771 (2007) 210-227.

[29] T. Yamaguchi, S. Matsushita, K. Motojima, F. Hirose, T. Osumi, MLDP, a novel PAT family protein localized to lipid droplets and enriched in the heart, is regulated by peroxisome proliferator-activated receptor alpha, J Biol Chem 281 (2006) 1423214240 .

[30] H. Wang, M. Bell, U. Sreenevasan, H. Hu, J. Liu, K. Dalen, C. Londos, T. Yamaguchi, M.A. Rizzo, R. Coleman, D. Gong, D. Brasaemle, C. Sztalryd, Unique regulation of adipose triglyceride lipase (ATGL) by perilipin 5, a lipid droplet-associated protein, J Biol Chem 286 (2011) 15707-15715.

[31] H. Wang, U. Sreenevasan, H. Hu, A. Saladino, B.M. Polster, L.M. Lund, D.W. Gong, W.C. Stanley, C. Sztalryd, Perilipin 5, a lipid droplet-associated protein, provides physical and metabolic linkage to mitochondria, J Lipid Res 52 (2011) 2159-2168.

[32] K. Kuramoto, T. Okamura, T. Yamaguchi, T.Y. Nakamura, S. Wakabayashi, H. Morinaga, M. Nomura, T. Yanase, K. Otsu, N. Usuda, S. Matsumura, K. Inoue, T. Fushiki, Y. Kojima, T. Hashimoto, F. Sakai, F. Hirose, T. Osumi, Perilipin 5, a Lipid Droplet-binding Protein, Protects Heart from Oxidative Burden by Sequestering Fatty Acid from Excessive Oxidation, J Biol Chem 287 (2012) 23852-23863. 
[33] Z. Zhou, S. Yon Toh, Z. Chen, K. Guo, C.P. Ng, S. Ponniah, S.C. Lin, W. Hong, P. Li, Cideadeficient mice have lean phenotype and are resistant to obesity, Nat Genet 35 (2003) 49-56.

[34] M. Hallberg, D.L. Morganstein, E. Kiskinis, K. Shah, A. Kralli, S.M. Dilworth, R. White, M.G. Parker, M. Christian, A functional interaction between RIP140 and PGC-1alpha regulates the expression of the lipid droplet protein CIDEA, Mol Cell Biol 28 (2008) 6785-6795.

[35] V. Puri, S. Ranjit, S. Konda, S.M. Nicoloro, J. Straubhaar, A. Chawla, M. Chouinard, C. Lin, A. Burkart, S. Corvera, R.A. Perugini, M.P. Czech, Cidea is associated with lipid droplets and insulin sensitivity in humans, Proc Natl Acad Sci U S A 105 (2008) 78337838.

[36] L. Xu, L. Zhou, P. Li, CIDE proteins and lipid metabolism, Arterioscler Thromb Vasc Biol 32 (2012) 1094-1098.

[37] J. Gong, Z. Sun, L. Wu, W. Xu, N. Schieber, D. Xu, G. Shui, H. Yang, R.G. Parton, P. Li, Fsp27 promotes lipid droplet growth by lipid exchange and transfer at lipid droplet contact sites, J Cell Biol 195 (2011) 953-963.

[38] J.Z. Li, J. Ye, B. Xue, J. Qi, J. Zhang, Z. Zhou, Q. Li, Z. Wen, P. Li, Cideb regulates dietinduced obesity, liver steatosis, and insulin sensitivity by controlling lipogenesis and fatty acid oxidation, Diabetes 56 (2007) 2523-2532.

[39] J. Ye, J.Z. Li, Y. Liu, X. Li, T. Yang, X. Ma, Q. Li, Z. Yao, P. Li, Cideb, an ER- and lipid droplet-associated protein, mediates VLDL lipidation and maturation by interacting with apolipoprotein B, Cell Metab 9 (2009) 177-190.

[40] K. Liu, S. Zhou, J.Y. Kim, K. Tillison, D. Majors, D. Rearick, J.H. Lee, R.F. FernandezBoyanapalli, K. Barricklow, M.S. Houston, C.M. Smas, Functional analysis of FSP27 protein regions for lipid droplet localization, caspase-dependent apoptosis, and dimerization with CIDEA, Am J Physiol Endocrinol Metab 297 (2009) 1395-1413.

[41] N. Nishino, Y. Tamori, S. Tateya, T. Kawaguchi, T. Shibakusa, W. Mizunoya, K. Inoue, R. Kitazawa, S. Kitazawa, Y. Matsuki, R. Hiramatsu, S. Masubuchi, A. Omachi, K. Kimura, M. Saito, T. Amo, S. Ohta, T. Yamaguchi, T. Osumi, J. Cheng, T. Fujimoto, H. Nakao, K. Nakao, A. Aiba, H. Okamura, T. Fushiki, M. Kasuga, FSP27 contributes to efficient energy storage in murine white adipocytes by promoting the formation of unilocular lipid droplets, J Clin Invest 118 (2008) 2808-2821.

[42] V. Puri, S. Konda, S. Ranjit, M. Aouadi, A. Chawla, M. Chouinard, A. Chakladar, M.P. Czech, Fat-specific protein 27 , a novel lipid droplet protein that enhances triglyceride storage, J Biol Chem 282 (2007) 34213-34218.

[43] G. Haemmerle, A. Lass, R. Zimmermann, G. Gorkiewicz, C. Meyer, J. Rozman, G. Heldmaier, R. Maier, C. Theussl, S. Eder, D. Kratky, E.F. Wagner, M. Klingenspor, G. Hoefler, R. Zechner, Defective lipolysis and altered energy metabolism in mice lacking adipose triglyceride lipase, Science 312 (2006) 734-737.

[44] R. Zechner, R. Zimmermann, T.O. Eichmann, S.D. Kohlwein, G. Haemmerle, A. Lass, F. Madeo, FAT SIGNALS--lipases and lipolysis in lipid metabolism and signaling, Cell Metab 15 (2012) 279-291.

[45] A.K. Ghosh, G. Ramakrishnan, C. Chandramohan, R. Rajasekharan, CGI-58, the causative gene for Chanarin-Dorfman syndrome, mediates acylation of lysophosphatidic acid, J Biol Chem 283 (2008) 24525-24533.

[46] A. Lass, R. Zimmermann, G. Haemmerle, M. Riederer, G. Schoiswohl, M. Schweiger, P. Kienesberger, J.G. Strauss, G. Gorkiewicz, R. Zechner, Adipose triglyceride lipasemediated lipolysis of cellular fat stores is activated by CGI-58 and defective in Chanarin-Dorfman Syndrome, Cell Metab 3 (2006) 309-319.

[47] C. Lefevre, F. Jobard, F. Caux, B. Bouadjar, A. Karaduman, R. Heilig, H. Lakhdar, A. Wollenberg, J.L. Verret, J. Weissenbach, M. Ozguc, M. Lathrop, J.F. Prud'homme, J. Fischer, Mutations in CGI-58, the gene encoding a new protein of the 
esterase/lipase/thioesterase subfamily, in Chanarin-Dorfman syndrome, Am J Hum Genet 69 (2001) 1002-1012.

[48] X. Yang, X. Lu, M. Lombes, G.B. Rha, Y.I. Chi, T.M. Guerin, E.J. Smart, J. Liu, The $\mathrm{G}(0) / G(1)$ switch gene 2 regulates adipose lipolysis through association with adipose triglyceride lipase, Cell Metab 11 (2010) 194-205.

[49] F. Zandbergen, S. Mandard, P. Escher, N.S. Tan, D. Patsouris, T. Jatkoe, S. Rojas-Caro, S. Madore, W. Wahli, S. Tafuri, M. Muller, S. Kersten, The G0/G1 switch gene 2 is a novel PPAR target gene, Biochem J 392 (2005) 313-324.

[50] S. Martin, K. Driessen, S.J. Nixon, M. Zerial, R.G. Parton, Regulated localization of Rab18 to lipid droplets: effects of lipolytic stimulation and inhibition of lipid droplet catabolism, J Biol Chem 280 (2005) 42325-42335.

[51] S. Ozeki, J. Cheng, K. Tauchi-Sato, N. Hatano, H. Taniguchi, T. Fujimoto, Rab18 localizes to lipid droplets and induces their close apposition to the endoplasmic reticulumderived membrane, J Cell Sci 118 (2005) 2601-2611.

[52] A.W. Cohen, B. Razani, W. Schubert, T.M. Williams, X.B. Wang, P. Iyengar, D.L. Brasaemle, P.E. Scherer, M.P. Lisanti, Role of caveolin-1 in the modulation of lipolysis and lipid droplet formation, Diabetes 53 (2004) 1261-1270.

[53] M. Drab, P. Verkade, M. Elger, M. Kasper, M. Lohn, B. Lauterbach, J. Menne, C. Lindschau, F. Mende, F.C. Luft, A. Schedl, H. Haller, T.V. Kurzchalia, Loss of caveolae, vascular dysfunction, and pulmonary defects in caveolin-1 gene-disrupted mice, Science 293 (2001) 2449-2452.

[54] M.A. Fernandez, C. Albor, M. Ingelmo-Torres, S.J. Nixon, C. Ferguson, T. Kurzchalia, F. Tebar, C. Enrich, R.G. Parton, A. Pol, Caveolin-1 is essential for liver regeneration, Science 313 (2006) 1628-1632.

[55] S. Le Lay, E. Hajduch, M.R. Lindsay, X. Le Liepvre, C. Thiele, P. Ferre, R.G. Parton, T. Kurzchalia, K. Simons, I. Dugail, Cholesterol-induced caveolin targeting to lipid droplets in adipocytes: a role for caveolar endocytosis, Traffic 7 (2006) 549-561.

[56] A. Pol, S. Martin, M.A. Fernandez, M. Ingelmo-Torres, C. Ferguson, C. Enrich, R.G. Parton, Cholesterol and fatty acids regulate dynamic caveolin trafficking through the Golgi complex and between the cell surface and lipid bodies, Mol Biol Cell 16 (2005) 2091-2105.

[57] B. Razani, T.P. Combs, X.B. Wang, P.G. Frank, D.S. Park, R.G. Russell, M. Li, B. Tang, L.A. Jelicks, P.E. Scherer, M.P. Lisanti, Caveolin-1-deficient mice are lean, resistant to dietinduced obesity, and show hypertriglyceridemia with adipocyte abnormalities, J Biol Chem 277 (2002) 8635-8647.

[58] S. Turro, M. Ingelmo-Torres, J.M. Estanyol, F. Tebar, M.A. Fernandez, C.V. Albor, K. Gaus, T. Grewal, C. Enrich, A. Pol, Identification and characterization of associated with lipid droplet protein 1: A novel membrane-associated protein that resides on hepatic lipid droplets, Traffic 7 (2006) 1254-1269.

[59] J.K. Zehmer, R. Bartz, B. Bisel, P. Liu, J. Seemann, R.G. Anderson, Targeting sequences of UBXD8 and AAM-B reveal that the ER has a direct role in the emergence and regression of lipid droplets, J Cell Sci 122 (2009) 3694-3702.

[60] J.K. Zehmer, R. Bartz, P. Liu, R.G. Anderson, Identification of a novel N-terminal hydrophobic sequence that targets proteins to lipid droplets, J Cell Sci 121 (2008) 1852-1860.

[61] C. Wu, C. Orozco, J. Boyer, M. Leglise, J. Goodale, S. Batalov, C.L. Hodge, J. Haase, J. Janes, J.W. Huss, 3rd, A.I. Su, BioGPS: an extensible and customizable portal for querying and organizing gene annotation resources, Genome Biol 10 (2009).

[62] J.E. Lattin, K. Schroder, A.I. Su, J.R. Walker, J. Zhang, T. Wiltshire, K. Saijo, C.K. Glass, D.A. Hume, S. Kellie, M.J. Sweet, Expression analysis of G Protein-Coupled Receptors in mouse macrophages, Immunome Res 4 (2008). 
[63] M. Paar, C. Jungst, N.A. Steiner, C. Magnes, F. Sinner, D. Kolb, A. Lass, R. Zimmermann, A. Zumbusch, S.D. Kohlwein, H. Wolinski, Remodeling of Lipid Droplets during Lipolysis and Growth in Adipocytes, J Biol Chem 287 (2012) 11164-11173.

[64] C. Guerra, R.A. Koza, H. Yamashita, K. Walsh, L.P. Kozak, Emergence of brown adipocytes in white fat in mice is under genetic control. Effects on body weight and adiposity, J Clin Invest 102 (1998) 412-420.

[65] A. Frontini, S. Cinti, Distribution and development of brown adipocytes in the murine and human adipose organ, Cell Metab 11 (2009) 253-256.

[66] A. Vitali, I. Murano, M.C. Zingaretti, A. Frontini, D. Ricquier, S. Cinti, The adipose organ of obesity-prone C57BL/6J mice is composed of mixed white and brown adipocytes, J Lipid Res 53 (2012) 619-629.

[67] M. Jimenez, G. Barbatelli, R. Allevi, S. Cinti, J. Seydoux, J.P. Giacobino, P. Muzzin, F. Preitner, Beta 3-adrenoceptor knockout in C57BL/6J mice depresses the occurrence of brown adipocytes in white fat, Eur J Biochem 270 (2003) 699-705.

[68] S. Cinti, Transdifferentiation properties of adipocytes in the adipose organ, Am J Physiol Endocrinol Metab 297 (2009) 977-986.

[69] S.N. Schreiber, D. Knutti, K. Brogli, T. Uhlmann, A. Kralli, The transcriptional coactivator PGC-1 regulates the expression and activity of the orphan nuclear receptor estrogenrelated receptor alpha (ERRalpha), J Biol Chem 278 (2003) 9013-9018.

[70] P. Puigserver, Z. Wu, C.W. Park, R. Graves, M. Wright, B.M. Spiegelman, A coldinducible coactivator of nuclear receptors linked to adaptive thermogenesis, Cell 92 (1998) 829-839.

[71] N. Viswakarma, S. Yu, S. Naik, P. Kashireddy, K. Matsumoto, J. Sarkar, S. Surapureddi, Y. Jia, M.S. Rao, J.K. Reddy, Transcriptional regulation of Cidea, mitochondrial cell death-inducing DNA fragmentation factor alpha-like effector $A$, in mouse liver by peroxisome proliferator-activated receptor alpha and gamma, J Biol Chem 282 (2007) 18613-18624.

[72] Y.J. Kim, S.Y. Cho, C.H. Yun, Y.S. Moon, T.R. Lee, S.H. Kim, Transcriptional activation of Cidec by PPARgamma2 in adipocyte, Biochem Biophys Res Commun 377 (2008) 297302.

[73] S. Rodriguez-Cuenca, S. Carobbio, V.R. Velagapudi, N. Barbarroja, J.M. MorenoNavarrete, F.J. Tinahones, J.M. Fernandez-Real, M. Oresic, A. Vidal-Puig, Peroxisome proliferator-activated receptor gamma-dependent regulation of lipolytic nodes and metabolic flexibility, Mol Cell Biol 32 (2009) 1555-1565.

[74] E.E. Kershaw, M. Schupp, H.P. Guan, N.P. Gardner, M.A. Lazar, J.S. Flier, PPARgamma regulates adipose triglyceride lipase in adipocytes in vitro and in vivo, Am J Physiol Endocrinol Metab 293 (2007) 1736-1745.

[75] E.P. Mottillo, A.E. Bloch, T. Leff, J.G. Granneman, Lipolytic Products Activate Peroxisome Proliferator-activated Receptor (PPAR) alpha and delta in Brown Adipocytes to Match Fatty Acid Oxidation with Supply, J Biol Chem 287 (2012) 2503825048.

[76] A. Marcinkiewicz, D. Gauthier, A. Garcia, D.L. Brasaemle, The phosphorylation of serine 492 of perilipin a directs lipid droplet fragmentation and dispersion, J Biol Chem 281 (2006) 11901-11909.

[77] N. Ariotti, S. Murphy, N.A. Hamilton, L. Wu, K. Green, N.L. Schieber, P. Li, S. Martin, R.G. Parton, Postlipolytic insulin-dependent remodeling of micro lipid droplets in adipocytes, Mol Biol Cell 23 (2012) 1826-1837.

[78] R. Mishra, M.S. Simonson, Saturated free fatty acids and apoptosis in microvascular mesangial cells: palmitate activates pro-apoptotic signaling involving caspase 9 and mitochondrial release of endonuclease G, Cardiovasc Diabetol 4 (2005). 
[79] H.P. Moore, R.B. Silver, E.P. Mottillo, D.A. Bernlohr, J.G. Granneman, Perilipin targets a novel pool of lipid droplets for lipolytic attack by hormone-sensitive lipase, J Biol Chem 280 (2005) 43109-43120.

[80] H.P. Guan, Y. Li, M.V. Jensen, C.B. Newgard, C.M. Steppan, M.A. Lazar, A futile metabolic cycle activated in adipocytes by antidiabetic agents, Nat Med 8 (2002) 11221128.

[81] S.L. Wijers, W.H. Saris, W.D. van Marken Lichtenbelt, Recent advances in adaptive thermogenesis: potential implications for the treatment of obesity, Obes Rev 10 (2009) 218-226.

[82] C.W. Meyer, M. Willershauser, M. Jastroch, B.C. Rourke, T. Fromme, R. Oelkrug, G. Heldmaier, M. Klingenspor, Adaptive thermogenesis and thermal conductance in wildtype and UCP1-KO mice, Am J Physiol Regul Integr Comp Physiol 299 (2010) 13961406.

[83] J.G. Granneman, M. Burnazi, Z. Zhu, L.A. Schwamb, White adipose tissue contributes to UCP1-independent thermogenesis, Am J Physiol Endocrinol Metab 285 (2003) 12301236.

[84] I.G. Shabalina, J. Hoeks, T.V. Kramarova, P. Schrauwen, B. Cannon, J. Nedergaard, Cold tolerance of UCP1-ablated mice: a skeletal muscle mitochondria switch toward lipid oxidation with marked UCP3 up-regulation not associated with increased basal, fatty acid- or ROS-induced uncoupling or enhanced GDP effects, Biochim Biophys Acta 1797 (2010) 968-980. 


\section{Figure Legends}

Figure 1. LD-protein gene expression in white and brown adipose tissue.

The mRNA levels of LD-proteins were measured by qPCR in selected adipose tissue depots of mice maintained at $22{ }^{\circ} \mathrm{C}$. The bars show the relative mRNA levels in interscapular (BAT, $\square$ ), subcutaneous (scWAT, $\square$ ), periovarian (gonWAT, $\square$ ) and

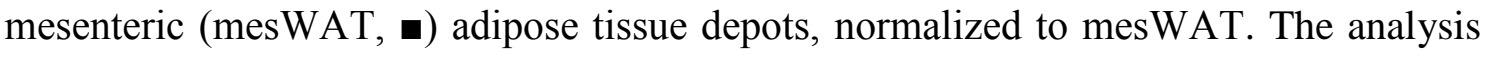
was performed in triplicate and represented with the means \pm S.E.M. One-way ANOVA with Bonferroni post-test was performed to determine significant differences with BAT $(* P<0.05 ; * * P<0.01 ; * * * P<0.001)$.

\section{Figure 2. Effect of cold exposure on LD-protein gene expression in adipose tissue.}

Sv129 female mice were maintained at $28{ }^{\circ} \mathrm{C}$ or $6{ }^{\circ} \mathrm{C}$ for 10 days and adipose tissue samples were collected for RNA extraction and histological analysis. (A) Changes induced by cold temperature on the expression of LD-proteins in the selected adipose tissue depots. Results were expressed as the normalised mRNA levels relative to $28{ }^{\circ} \mathrm{C}$. Means \pm S.E.M., with asterisks indicating significant changes induced by cold exposure $(* P<0.05 ; * * P<0.01 ; * * * P<0.001)$. (B) Immunohistochemical analysis of UCP1 and CIDEA in periovarian adipose tissue of mice maintained at $28{ }^{\circ} \mathrm{C}$ or $6{ }^{\circ} \mathrm{C}$. The representative images show the heterogeneity of the WAT depot, and the cold-induced increase in UCP1 and CIDEA immunoreactive cells as well as in the number of multilocular adipocytes.

Figure 3. LD dynamics in differentiated 3T3-L1 cells under sustained $\beta$-adrenergic stimulation.

(A, C, E) Time-lapse imaging of LD dynamics in 3T3-L1 adipocytes. Cells were stained with BODIPY 493/503 and treated with IBMX $(500 \mu \mathrm{M})$ and isoproterenol $(10 \mu \mathrm{M})$. Zstack images were acquired every 2 min for 15 hours, and are showed as maximum intensity projections of selected time points. (A) Depletion of the neutral lipid stores in a cell exposed to persistent lipolysis due to prolonged $\beta$-adrenergic stimulation. The formation of mLDs $(<1 \mu \mathrm{m})$ is observed throughout the cytoplasm during the first stages and they are later consumed. (B) Quantification of the different cellular responses observed during the sustained $\beta$-adrenergic stimulation $(n=45$ cells in 6 independent experiments). (C) Cell experiencing a LD remodelling cycle with LD size reduction by lipolysis followed by mLD formation and their later enlargement by lipid transference. 
The LDs monitored in (D) are indicated by numbers. Green arrows highlight a selected LD under lipolysis and red arrows a growing LD. (D) Quantification of the changes in the diameter of LDs undergoing lipolysis (1,2 and 3) or growth (4 and 5). LD reduction by lipolysis continues long after the initiation of the LD enlargement process. (E) Detail of the LD enlargement process by slow transfer of lipids among adjacent LDs. Most of the cells produced mLDs, which were later depleted by lipolysis (A) or enlarged by lipid transference $(\mathrm{C}, \mathrm{E})$. (E)

\section{Figure 4. Glycerol kinase and Aquaporin 7 gene expression in adipose tissue.}

The glycerol released by lipolysis can be exported through its transporter Aqp7 or recycled into TAG. GYK promotes the recycling of lipolysis products into TAG, being indicative of the existence of post-lipolytic mLD formation. (A) Increase in Gyk and Aqp7 expression in WAT depots during cold acclimatization. The mRNA analysis represented as means \pm S.E.M., $P$ indicates significance vs $28{ }^{\circ} \mathrm{C}(* P<0.05 ; * * P<$ 0.01 ; ***P $<0.001$ ). (B) Gyk and Aqp7 mRNA levels in brown and white adipose depots of mice kept at $22^{\circ} \mathrm{C}$. $(* * * P<0.001$ significance vs BAT).

\section{Figure 5. Proposed model of adipocyte LD remodelling during cold acclimatization}

(A) The FAs release during prolonged lipolysis stimulation in adipocytes can be exported to the extracellular medium, consumed by $\beta$-oxidation or re-esterified into TAG or other lipids. The futile cycle of TAG hydrolysis and re-synthesis is favoured by the expression of Gyk, which promotes the recycling of glycerol and FAs for TAG synthesis and mLD formation. The full cycle involved in post-lipolytic mLDs formation involves the transformation of chemical energy into heat. (B) A hypothetical role for CIDE proteins in lipolysis. By promoting TAG traffic between LDs, CIDE proteins might constitute a network of LDs were the TAG efficiently hydrolyzed in small LDs would be continuously replenished from larger LDs. The control of the TAG transfer direction could be important for the acquisition of a unilocular or multilocular phenotype. (C) Schematic representation of a potential mechanism for unilocular to multilocular transformation during white adipocyte transdifferentiation. Prolonged cold exposure would induce the LD remodelling cycle observed during sustained $\beta$ adrenergic stimulation, with the formation of mLDs from lipolytically-released FAs and their later enlargement until the multilocular morphology is achieved. 
Supplemental movie S1. Lipid droplet dynamics in differentiated 3T3-L1 cells under sustained $\beta$-adrenergic stimulation.

Differentiated 3T3-L1 cell stained with BODIPY 493/503 and treated with IBMX and isoproterenol. Z-stack images were acquired every $2 \mathrm{~min}$ for 15 hours, and are represented as maximum intensity projections. The initial LDs are consumed by lipolysis, while newly synthesized mLDs $(<1 \mu \mathrm{m})$ appear throughout the cytoplasm. After 4-6 hours the mLDs undergo an enlargement process by lipid transference between neighbour LDs, likely to be triggered by CIDE proteins. In the upper left side of the cell, mLD motion during the LD growing phase can be observed. 


\begin{tabular}{|c|c|c|}
\hline Gene & Description & Refs. \\
\hline $\begin{array}{c}\text { Plin1 } \\
\text { (Perilipin) }\end{array}$ & $\begin{array}{l}\text { Expressed in adipose tissue. Subcellular localization restricted to LDs. } \\
\text { Regulates lipolysis. } \beta \text {-adrenergic stimulus promotes PKA-mediated } \\
\text { phosphorylation of PLIN1, stimulating ATGL and HSL lipase activity on } \\
\text { LDs. }\end{array}$ & [16-19] \\
\hline $\begin{array}{l}\text { Plin2 } \\
(\text { ADRP, } \\
\text { ADFP) }\end{array}$ & $\begin{array}{l}\text { Ubiquitously expressed. Subcellular localization restricted to LDs. } \\
\text { Essential role in LD formation and maintenance in non-adipocyte cells. }\end{array}$ & [20-23] \\
\hline $\begin{array}{l}\text { Plin3 } \\
\text { (TIP47) }\end{array}$ & $\begin{array}{l}\text { Ubiquitously expressed. Involved in early stages of LD formation. } \\
\text { Progressively substituted by PLIN2 and later PLIN1 during LD maturation } \\
\text { in adipocytes. }\end{array}$ & {$[24,25]$} \\
\hline $\begin{array}{c}\text { Plin4 } \\
(\mathrm{S} 3-12)\end{array}$ & Highly enriched in adipose tissue. Coats newly formed LDs. & {$[25,26]$} \\
\hline $\begin{array}{l}\text { Plin5 } \\
\text { (Oxpat, } \\
\text { Lsdp5, } \\
\text { MLDP) }\end{array}$ & $\begin{array}{l}\text { Expressed in highly oxidative tissues like heart and BAT. Possible } \\
\text { regulation of ATGL-mediated lipolysis. Suggested protective role against } \\
\text { excessive production of reactive oxygen species by controling FA } \\
\text { mitochondrial oxidation and their incorporation to LDs. }\end{array}$ & [27-32] \\
\hline Cidea & $\begin{array}{l}\text { Highly expressed in brown adipose tissue. Promotes LD enlargement by } \\
\text { LD-LD lipid transference. Cide (A, B or C) deficient mice are resistant to } \\
\text { obesity. }\end{array}$ & [33-37] \\
\hline Cideb & Enriched in liver. Involved in lipoprotein production in hepatocytes. & {$[36,38,39]$} \\
\hline $\begin{array}{c}\text { Cidec } \\
(\mathrm{FSP} 27)\end{array}$ & $\begin{array}{l}\text { Expressed in adipose tissue. Promotes LD enlargement through LD-LD } \\
\text { transference of lipids. Required for unilocular LD formation in WAT. }\end{array}$ & $\begin{array}{l}{[36,37,40-} \\
42]\end{array}$ \\
\hline $\begin{array}{l}\text { Pnpla2 } \\
\text { (ATGL) }\end{array}$ & $\begin{array}{l}\text { Ubiquitously expressed. Cytosolic and LD localizaton. Catalyses the initial } \\
\text { step of lipolysis by hydrolising the first FA molecule of TAG. }\end{array}$ & {$[43,44]$} \\
\hline $\begin{array}{l}\text { Abhd5 } \\
(\mathrm{CGI}-58)\end{array}$ & $\begin{array}{l}\text { Interacts with PLIN1 under basal conditions. PKA-mediated PLIN1 } \\
\text { phosphorylation promotes CGI-58 release, which induce lipolysis by } \\
\text { activating ATGL. Inactive CGI-58 variants cause neutral lipid storage } \\
\text { disease with ichthyosis. Possesses lysophosphatidic acid acyltransferase } \\
\text { activity. }\end{array}$ & [45-47] \\
\hline G0s2 & $\begin{array}{l}\text { Ubiquitously expressed. Prevents lipolysis by inhibiting ATGL through a } \\
\text { direct interaction. Increased WAT expression after feeding. Increased liver } \\
\text { expression by fasting or PPAR } \alpha \text { agonists. }\end{array}$ & {$[48,49]$} \\
\hline Rab18 & $\begin{array}{l}\text { Small GTPase involved in membrane trafficking and LD dynamics. } \\
\text { Localized in the ER and LDs. Possible implication in both lipolytic and } \\
\text { lipogenic processes. }\end{array}$ & {$[50,51]$} \\
\hline Cav1 & $\begin{array}{l}\text { Essential component of plasma membrane caveolae. Integral membrane } \\
\text { protein containing a hydrophobic hairpin domain insertable in both } \\
\text { membrane bilayers or LD monolayers. Localized in LD under certain } \\
\text { circumstances such as liver regeneration, lipid loading or brefeldin A } \\
\text { treatment. Lean phenotype in Cav1-KO mice. }\end{array}$ & {$[52-57]$} \\
\hline $\begin{array}{l}\text { Mettl7b } \\
(\text { ALDI) }\end{array}$ & \multirow{2}{*}{$\begin{array}{l}\text { Unknown function. Partial homology with S-adenosyl-L-methionine- } \\
\text { dependent methyltransferases. Integral membrane proteins able to bind } \\
\text { LDs through a hydrophobic hairpin domain. Localized in both ER and LD } \\
\text { membranes. }\end{array}$} & [58] \\
\hline $\begin{array}{l}\text { Mettl7a1 } \\
(\mathrm{AAMb})\end{array}$ & & {$[59,60]$} \\
\hline
\end{tabular}

Table 1. Lipid droplet proteins. 
Figure 2
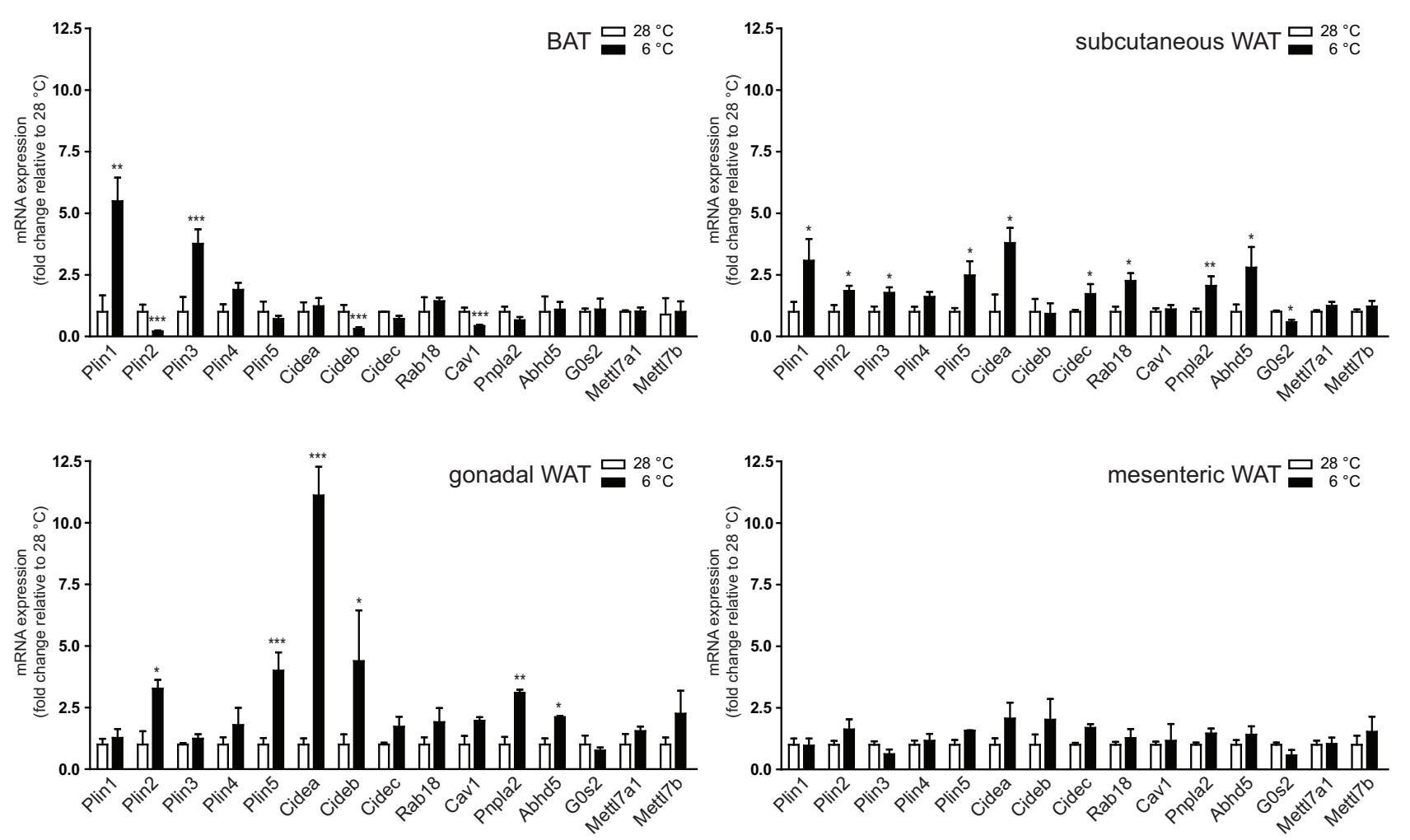

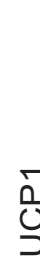

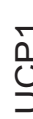

10.0.

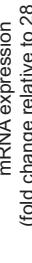

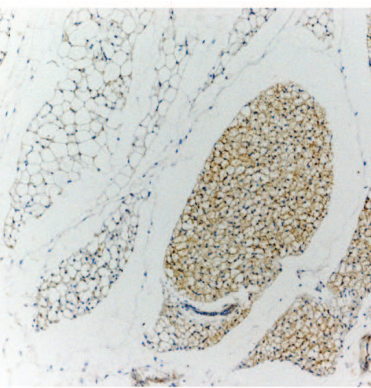

$=$

$$
\text { 跑 }
$$

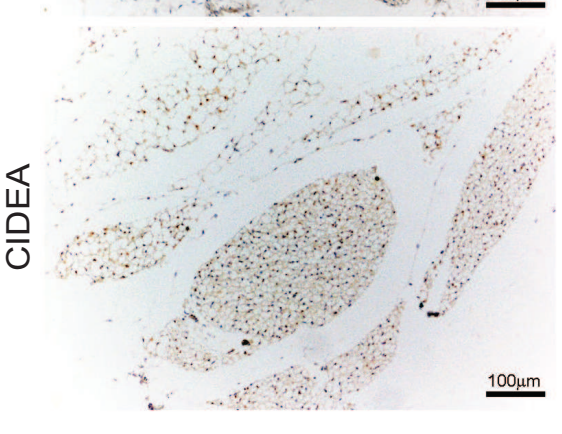

$28^{\circ} \mathrm{C}$
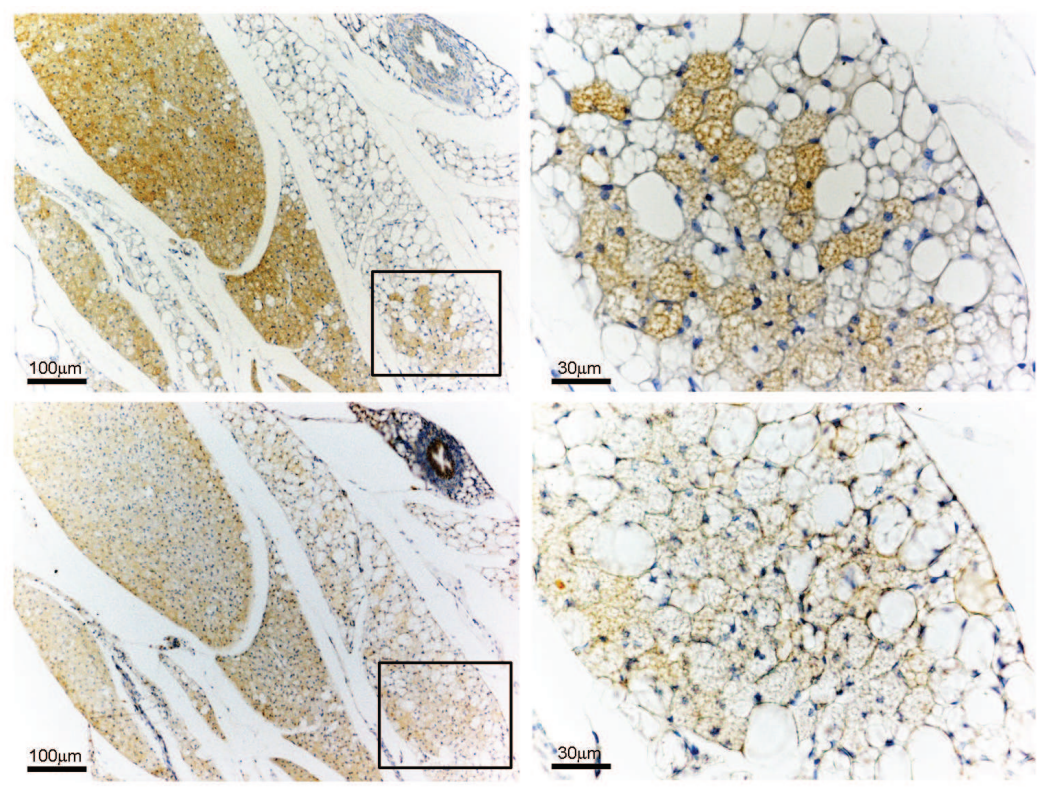
Figure 4

A

B
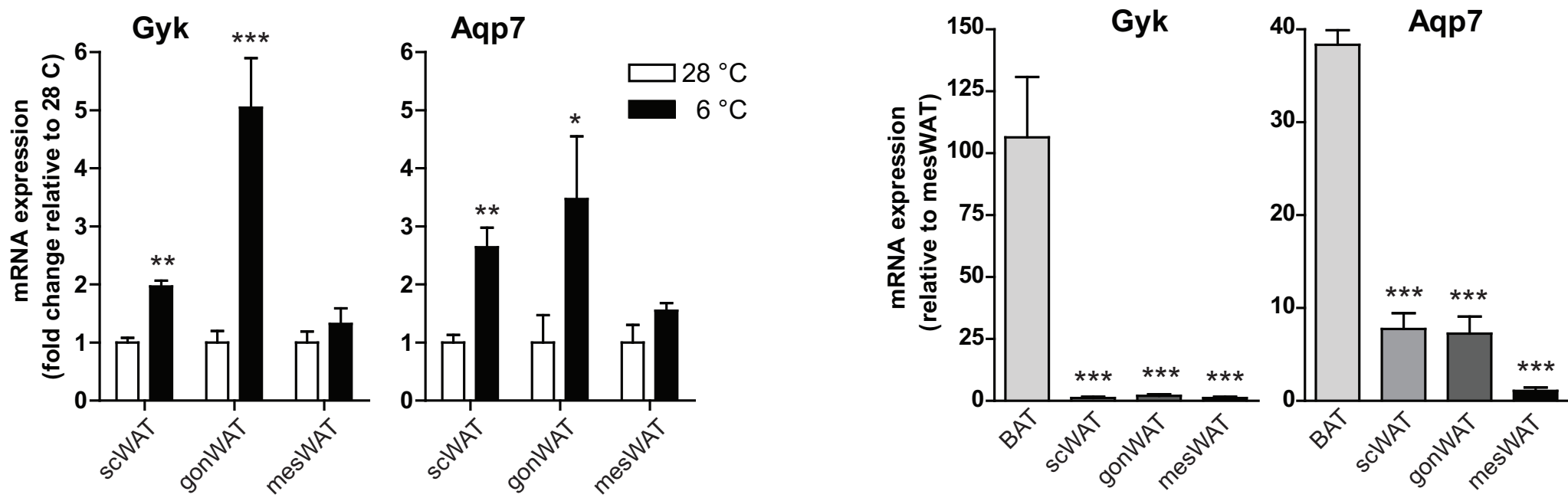


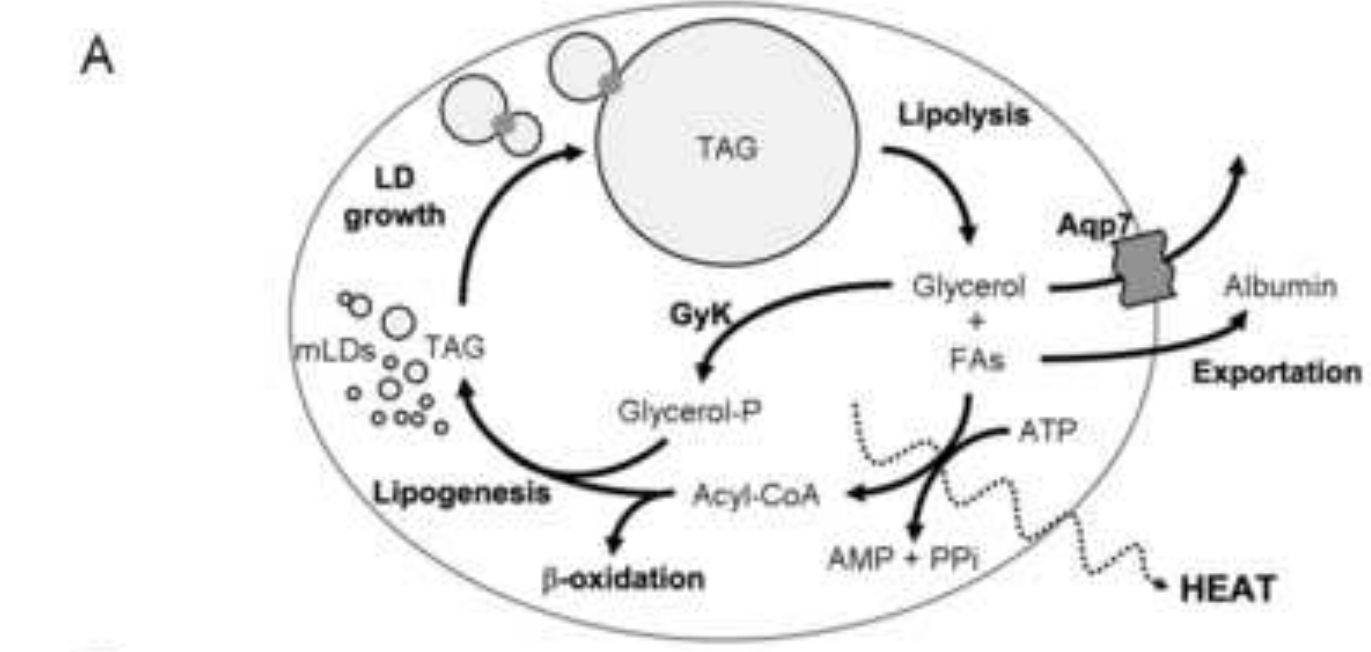

\section{B}

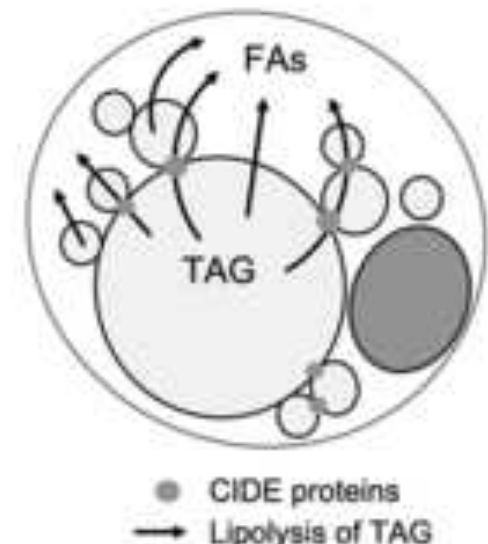

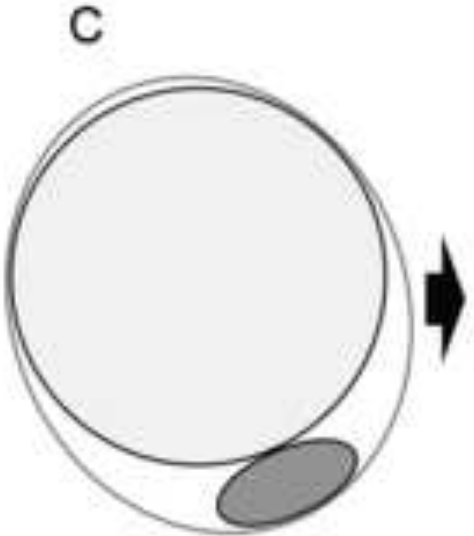

unilocular adipocyte

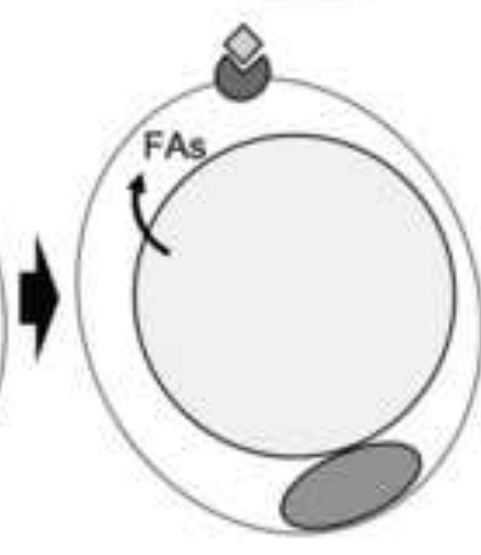

lipolysis

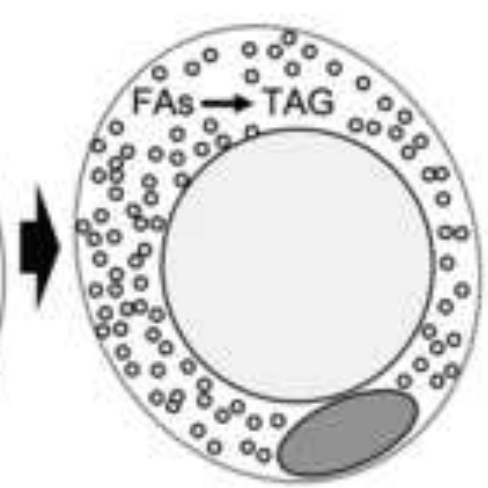

mLD formation

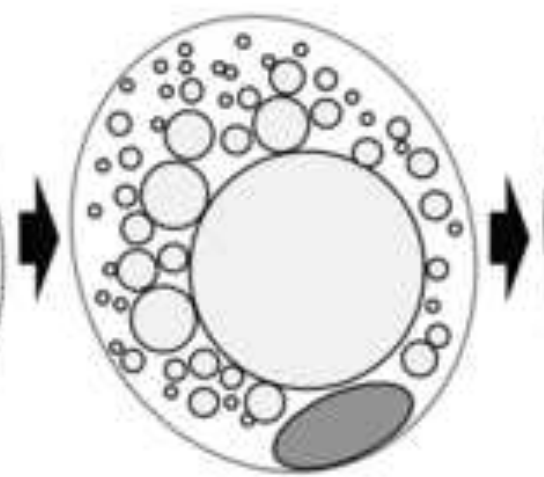

LD enlargement

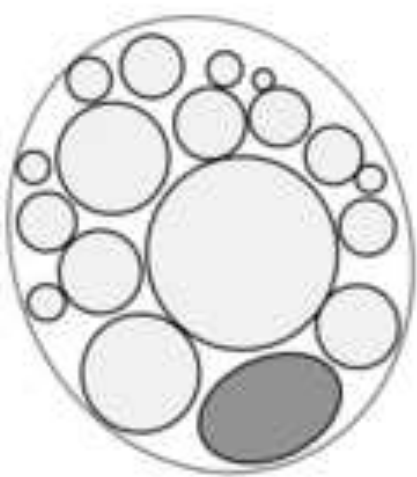

multilocular adipocyte 


\begin{tabular}{|c|c|}
\hline Gene & Sequence $(F, R)$ \\
\hline \multirow{2}{*}{ Plin 1} & GGCTCTGGGAAGCATCGA \\
\hline & GGCCTTGGGAGCCTTCTG \\
\hline \multirow{2}{*}{ Plin 2} & TGGCAGCAGCAGTAGTGGAT \\
\hline & AGCTCACCAAGGGCAGGTT \\
\hline \multirow{2}{*}{ Plin 3} & AAACAGGGTGTGGACCAGAG \\
\hline & GGCTTAGCTGGGTCCTTTTC \\
\hline \multirow{2}{*}{ Plin4 } & GCTGACACCAAAАСССТTGT \\
\hline & АССАСАСТССТССАСТGACC \\
\hline \multirow{2}{*}{ Plin5 } & TCCTGCCCGTCAAAGGGATCTGA \\
\hline & GGACATTCTGCTGTGTGGCGCT \\
\hline \multirow{2}{*}{ Cidea } & AAGCTTCAAGGCCGTGTTA \\
\hline & CTGTAGCTGTGCCCTGGTTA \\
\hline \multirow{2}{*}{ Cideb } & GCTGGAGCCCCAAGAGTGGGA \\
\hline & GGTGATGCGGGCGATGTCCT \\
\hline \multirow{2}{*}{ Cidec } & GCCCCCATCAGAACAGCGCA \\
\hline & AGGTTACCCGGGCCACATCG \\
\hline \multirow{2}{*}{ Pnpla2 } & TGTGGCCTCATTCCTCCTAC \\
\hline & TCGTGGATGTTGGTGGAGCT \\
\hline \multirow{2}{*}{ Abhd5 } & TGACAGTGATGCGGAAGAAG \\
\hline & AGATCTGGTCGCTCAGGAAA \\
\hline \multirow{2}{*}{ G0s2 } & AGTGCTGCСTCTCTTCCCAC \\
\hline & TTTCCATCTGAGCTCTGGGC \\
\hline \multirow{2}{*}{ Rab18 } & СTCTGAAGATACTCATCATCGG \\
\hline & ССTCTCTTGACCAGCTGTATCCCA \\
\hline \multirow{2}{*}{ Cav1 } & AACATCTACAAGCCCAACAACAAGG \\
\hline & GGTTCTGCAATCACATCTTCAAAGTC \\
\hline \multirow{2}{*}{ Mettl7b } & GGCCGGGAGGCCTACTGTTCT \\
\hline & ACTCGCTGCCACAGGAAGGC \\
\hline \multirow{2}{*}{ Mettl7a1 } & TCCTGGACATTGGTGCGGCCC \\
\hline & GGAAGCCTGGAACCAGCTCGGA \\
\hline \multirow{2}{*}{ Gyk } & TCCAACATCAAAGCCATTGGT \\
\hline & AGAGGCTCTCCGGTGACCTT \\
\hline \multirow{2}{*}{ Aqp7 } & AGCACTTCAGAGAACCTACTTCATAAGA \\
\hline & TGCAGTGCGGAGATGGTAATT \\
\hline
\end{tabular}

Supplemental Table 1. qPCR primer pairs used in this study. 
Supplemental movie S1. Lipid droplet dynamics in differentiated 3T3-L1 cells under sustained $\beta$-adrenergic stimulation.

Differentiated 3T3-L1 cell stained with BODIPY 493/503 and treated with IBMX and isoproterenol. Z-stack images were acquired every $2 \mathrm{~min}$ for 15 hours, and are represented as maximum intensity projections. The initial LDs are consumed by lipolysis, while newly synthesized mLDs $(<1 \mu \mathrm{M})$ appear throughout the cytoplasm. After 4-6 hours the mLDs experience an enlargement process by lipid transference between neighbour LDs, likely to be triggered by CIDE proteins. In the upper left side of the cell, the reorganization of $\mathrm{mLD}$ motion during the $\mathrm{LD}$ growing phase can be observed. 